\title{
Investigation of de novo cholesterol synthetic capacity in the gonads of goldfish (Carassius auratus) exposed to the phytosterol beta-sitosterol
}

\author{
Rainie L Sharpe*1, Melissa Drolet ${ }^{2}$ and Deborah L MacLatchy ${ }^{1}$
}

\author{
Address: ${ }^{1}$ Canadian Rivers Institute and Department of Biology, University of New Brunswick, PO Box 5050, 100 Tucker Park Road, Saint John, \\ NB, E2L 4L5, Canada and 2Department of Physical Sciences University of New Brunswick, PO Box 5050, 100 Tucker Park Road, Saint John, NB, \\ E2L 4L5, Canada \\ Email: Rainie L Sharpe* - rainie.sharpe@unb.ca; Melissa Drolet - melissa.drolet@unb.ca; Deborah L MacLatchy - maclatch@unbsj.ca \\ * Corresponding author
}

Published: 21 November 2006

Reproductive Biology and Endocrinology 2006, 4:60 doi:10.1 186/1477-7827-4-60

This article is available from: http://www.rbej.com/content/4/I/60

(C) 2006 Sharpe et al; licensee BioMed Central Ltd.

This is an Open Access article distributed under the terms of the Creative Commons Attribution License (http://creativecommons.org/licenses/by/2.0), which permits unrestricted use, distribution, and reproduction in any medium, provided the original work is properly cited.
Received: 26 July 2006

Accepted: 21 November 2006

\begin{abstract}
Total and intra-mitochondrial gonadal cholesterol concentrations are decreased in fish exposed to the phytoestrogen beta-sitosterol (beta-sit). The present study examined the potential for beta-sit to disrupt de novo cholesterol synthesis in the gonads of goldfish exposed to $200 \mathrm{microgram} / \mathrm{g}$ beta-sit and 10 microgram/g I 7 beta-estradiol (E2; estrogenic control) by intra-peritoneal Silastic ${ }^{\circledR}$ implants for 21 days. The de novo cholesterol synthetic capacity was estimated by incubating gonadal tissue with I4C-acetate for a period of 18 hours, followed by chloroform/methanol lipid extraction and thin layer chromatography (TLC) lipid separation. Lipid classes were confirmed using infrared spectroscopy. Plasma testosterone $(T)$ and total cholesterol concentration were measured and gonadosomatic index (GSI) was calculated. Plasma $T$ was significantly reduced in male beta-sit-treated fish compared to control and E2-treated fish $(\mathrm{P}<0.00 \mathrm{I})$. I4C-Acetate incorporation into cholesterol and cholesterol esters was not significantly different among treatment groups for male and female fish, however, 14C-enrichment was higher than expected in both triglycerides (TG) and free fatty acids (FFA). FFA incorporation was significantly higher in male control fish than either beta-sit or E2 treatments $(p=0.005)$. Plasma cholesterol concentration was significantly increased in the male beta-sit treatment group compared to controls $(p=0.027)$. These results indicate gonadal de novo cholesterol biosynthetic capacity is not disrupted by betasit or E2 treatment in early recrudescing male or female goldfish, while plasma cholesterol and steroid concentrations are sensitive to beta-sit exposure.
\end{abstract}

\section{Background}

Cholesterol is the precursor to all steroid hormones, such as estrogens, androgens, and corticosteroids [1]. In fish, as in other vertebrate species, cholesterol is obtained by dietary intake, release from intracellular stores or by de novo synthesis [2]. Cholesterol absorbed at the intestines is esterified with free fatty acids to form hydrophobic cho- lesterol esters (CEs), which are transported in the plasma in association with lipoproteins to sites of metabolism or storage $[3,4]$. At the tissues, receptor-mediated lipoprotein endocytosis delivers cholesterol to the intracellular environment for immediate use or re-esterification for intracellular storage [5]. While exogenous cholesterol is obtained in this way by most steroidogenic tissues (such 
as the adrenal and ovary), some tissues (such as the testis) differentially utilize de novo synthesized cholesterol as a substrate for steroid biosynthesis $[2,6]$. The definitive mechanisms of cholesterol metabolism in fish are believed to be highly similar to mammals, although comprehensive information on lipid dynamics in teleost species is limited. Cholesterol biosynthesis is believed to proceed by the same pathway in fish as in higher vertebrates [7]. A number of reviews on animal $[6,8,9]$ and fish [10] lipoprotein dynamics indicate structure is similar, although TG content is elevated at the expense of cholesterol esters in teleost lipoproteins. Fish plasma is considered hypercholesterolemic relative to higher vertebrates, with 2-6x higher circulating cholesterol concentrations a normal physiological condition in fish species [11]. The traditional detrimental affects associated with high plasma cholesterol such as coronary lesions and plaque formation are notably absent in fish species, presenting an interesting and stark contrast to the human condition.

De novo cholesterol synthesis begins with the production of acetyl CoA via acetate or citrate. Acetyl CoA is subsequently transformed to 3-hydroxy-3-methylglutaryl-CoA (HMG CoA), mevalonate, squalene, lanosterol and ultimately cholesterol via a number of enzymatic transformations (for a detailed summary see [12]). The newly synthesized cholesterol (Figure 1A) can then enter tissuespecific biosynthetic pathways such as steroidogenesis, or be incorporated into plasma membranes or esterified for intracellular storage. The relative contribution of de novo cholesterol synthesis to the total cholesterol pool in endocrine organs such as the gonads is generally not known. Ovarian tissue in mammals has been shown to utilize de novo TG and cholesterol synthesis during the pre-ovulatory phase of gonadal development, doing so preferentially over lipoprotein uptake $[2,13]$. Testis cholesterol is preferentially sourced from de novo synthesis, while the adrenal and ovary appear to revert to endogenous synthesis only if circulating concentrations are limiting [2]. Preferences of lipoprotein-derived or de novo synthesized cholesterol by fish endocrine tissues are presumably similar to mammalian tissues, however, direct studies on fish species are lacking.

The phytosterol $\beta$-sitosterol ( $\beta$-sit) very closely resembles cholesterol, differing only by an ethyl group on carbon 24 (Figure 1B). $\beta$-sit disrupts normal endocrine system function in fish by decreasing steroidogenic biosynthetic capacity [14] and disrupting plasma cholesterol concentrations and mitochondrial translocation to the steroidogenic pathway $[15,16]$. $\beta$-Sit has estrogenic properties as evidenced by the induction of the normally quiescent vitellogenin gene in male fish [17]. The capacity for plant sterols to affect de novo cholesterol synthesis is known to occur in the human disorder sitosterolemia, a condition where abnormally high concentrations of plant sterols accumulate in the plasma and tissues. Sitosterolemic patients experience impaired whole body de novo cholesterol synthesis by down-regulation of key synthetic enzymes $[18,19]$, and this sensitivity suggests de novo cholesterol synthesis in other species may also be impaired by phytosterol exposure. Previous studies have identified changes in cholesterol availability following phytosterol exposure [12], however, a lack of information on preferred substrate (exogenous or de novo synthesized cholesterol) in the gonads impedes further studies to determine mechanisms of endocrine disruption.

The present study examined endogenous cholesterol synthesis in the gonads of male and female goldfish exposed to $\beta$-sit and $17 \beta$-estradiol (an estrogenic control; Figure 1C) to determine if de novo cholesterol synthetic capacity was impaired relative to non-exposed fish. Further, the relative contribution of de novo cholesterol synthesis to the reproductive steroidogenic pathway is unknown in fish; therefore, this study also aimed to assess the contribution of de novo synthesis to the total cholesterol substrate pool.

\section{Methods}

All chemicals were purchased from Sigma-Aldrich (Oakville, ON, Canada) unless otherwise specified.

\section{Fish}

Goldfish (Carassius auratus) were purchased from Aleong International (Mississauga, ON, Canada) and acclimated to lab conditions in 66 - $\mathrm{L}$ flow-through tanks $\left(10-16^{\circ} \mathrm{C}\right.$ de-chlorinated City of Saint John water). During holding, fish were held on a 12:12 light:dark photoperiod and fed commercial trout pellets ad libitum (Corey Feed Mills, Fredericton, NB, Canada) every other day. Fish were transferred to experimental tanks two weeks prior to the start of the experiment.

\section{Implants}

Fish were exposed to $200 \mu \mathrm{g} / \mathrm{g} \beta$-sit (97\% pure synthetic $\beta$-sitosterol, catalogue \# S1270) or $10 \mu \mathrm{g} / \mathrm{g} 17 \beta$-estradiol $\left(\mathrm{E}_{2}\right.$; catalogue \# E8875) via Silastic ${ }^{\circledR}$ implants. This mode of in vivo dose delivery has been established as an effective exposure route for goldfish $[15,16]$ and implants have been shown to continuously release consistent doses over time $[20,21]$.

\section{Exposures}

Fish were allocated among the tanks such that there were 12 fish per tank during the exposure, with a random sex ratio (tubercles were not visible for sexing at the time of implanting). Fish were anaesthetized in 0.05\% TMS (tricaine methane sulfonate; Syndel International, Vancouver, BC, Canada). Fish weights and lengths were recorded fol- 

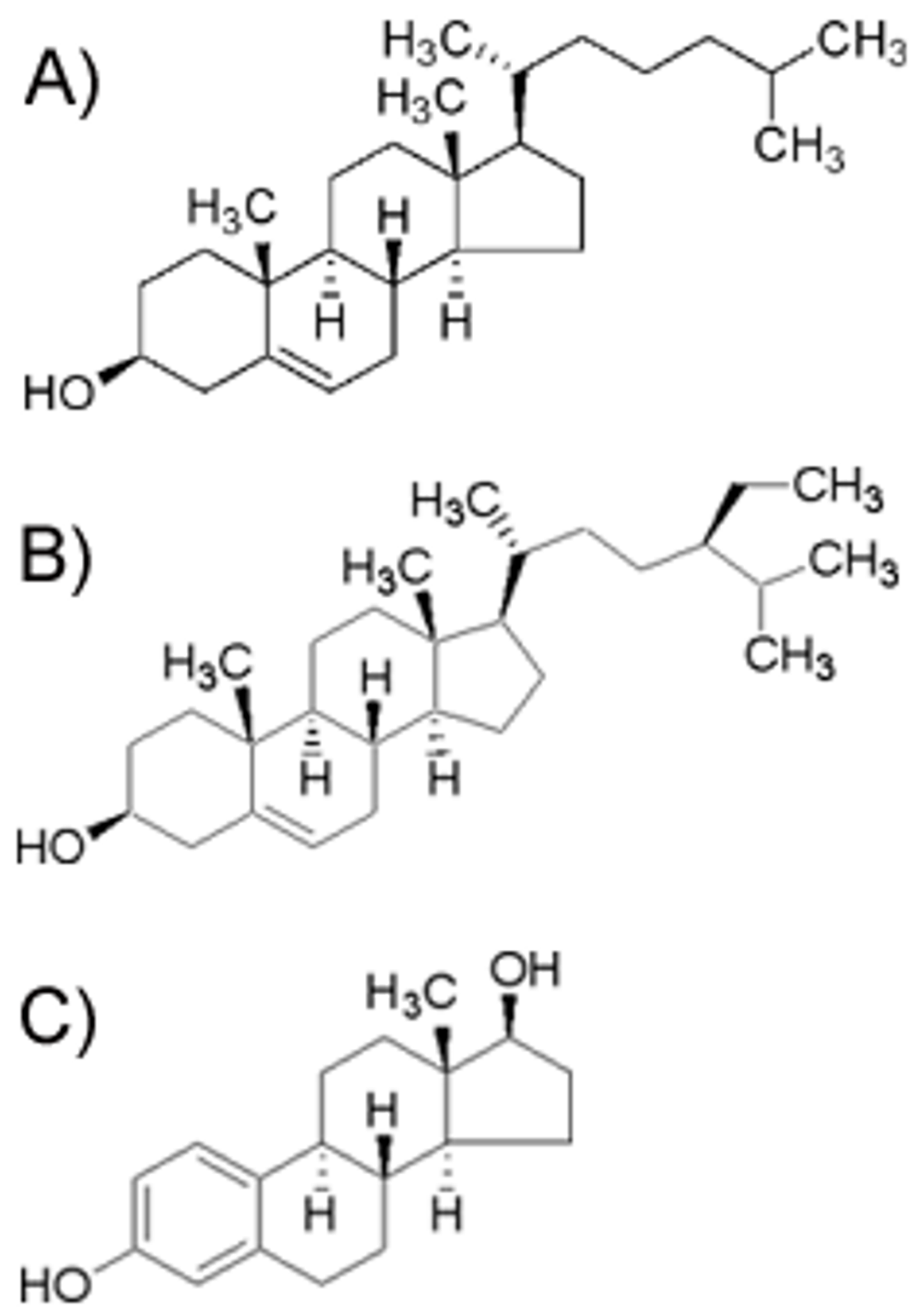

Figure I

Chemical structures of $(A)$ cholesterol $(B) \beta$-sitosterol $\left(\beta\right.$-sit), and $(C)$ I7 $\beta$-estradiol $\left(E_{2}\right)$. 
lowed by intra-peritoneal implanting of the Silastic ${ }^{\circledR}$ pellets containing either $0 \mu \mathrm{g} / \mathrm{g}$ (control), $200 \mu \mathrm{g} / \mathrm{g} \beta$-sit or 10 $\mu \mathrm{g} / \mathrm{g} \mathrm{E}_{2}$.

During the exposure, fish were held at $15-16^{\circ} \mathrm{C}$ and 14:10 light:dark photoperiod. The fish were fed $1.5 \%$ body weight daily during the exposure.

At the time of sampling, fish had been implanted for 21 days. Fish were bled by caudal puncture and plasma was separated by centrifugation and stored at $-20^{\circ} \mathrm{C}$ until steroids were extracted and cholesterol was measured. Weights $(0.1 \mathrm{~g})$ and lengths $(\mathrm{mm})$ were recorded and the gonads were removed, weighed $(0.01 \mathrm{~g})$ and immediately used in the de novo incubation. Following the incubation, gonads were frozen at $-80^{\circ} \mathrm{C}$ until the cholesterol assay was performed. Gonadosomatic indices (GSI) were calculated as per the equation:

GSI $(\%)=[$ gonad weight $(\mathrm{g}) /$ body weight $(\mathrm{g})] \times 100$.

\section{Radioimmunoassay}

Plasma hormones were extracted and testosterone (T) concentrations were measured by radioimmunoassay (RIA) [22]. A 45-minute incubation was performed at $4{ }^{\circ} \mathrm{C}$ after addition of $200 \mu \mathrm{L}$ of charcoal solution and prior to the 12-minute centrifugation at $1900 \mathrm{~g}$. This extra step was added to the protocol to stabilize and standardize counts throughout the assay. Radio-labelled $[1,2,6,7-3 \mathrm{H}]$-testosterone was purchased from Amersham-Pharmacia (Baie d'Urfé, QC, Canada). Antibodies to $\mathrm{T}$ were purchased from Medicorp (Montreal, QC, Canada) and cross-reactivity is reported as 35\% with dehydroepitestosterone and $<0.1 \%$ with other major steroids [23]. Both intra- and inter-assay variability were within acceptable limits (< $10 \%)$.

\section{De novo incubation}

Approximately $25 \mathrm{mg}$ of gonadal tissue were cut into two pieces and placed in wells on a 24 -well cell cluster plate (performed in duplicate for each gonad; Fisher Scientific, Nepean, ON, Canada). Each well received $1 \mathrm{~mL}$ of incubation solution which consisted of Medium 199 (M199; Sigma catalogue \#M2520) containing $5 \mu \mathrm{Ci}$ of acetic acidUL-14 C (catalogue \#314641). The plates were incubated for 18 hours at $18^{\circ} \mathrm{C}$ after which the incubation solution was removed and counted for total radioactivity. The samples were washed with $1.5 \mathrm{~mL}$ of wash solution (M199 and $2 \mathrm{mM}$ unlabelled sodium acetate) which was removed and counted for total radioactivity. The tissue samples were stored at $-80^{\circ} \mathrm{C}$ until the cholesterol assay was performed.

\section{Cholesterol assay}

Cholesterol was extracted from gonadal tissue using a modified chloroform/methanol extraction method [24]. In brief, samples were homogenized in liquid $\mathrm{N}_{2}$ using a mortar and pestle. Lipids were subsequently extracted by adding $3.5 \mathrm{~mL}$ chloroform, $4.5 \mathrm{~mL}$ methanol and $2 \times 10^{4}$ dpm $1 \alpha, 2 \alpha[\mathrm{N}]-3 \mathrm{H}$-cholesterol (for recovery estimation; \#C8794) to each sample. The tubes were mixed and left to settle before adding an additional $2 \mathrm{~mL}$ of chloroform. The tubes were mixed and left to settle before adding $3 \mathrm{~mL}$ of $2 \mathrm{M} \mathrm{KCl}$ with $5 \mathrm{mM}$ EDTA. Once settled, the bottom phase was transferred to a new test tube and washed twice with a 1:2 mix of methanol: $0.9 \% \mathrm{NaCl}$. The chloroform was evaporated under $\mathrm{N}_{2}$ gas and the samples were re-suspended in $40 \mu \mathrm{l}$ of chloroform for use in thin-layer chromatography (TLC).

Samples were spotted $(10 \mu \mathrm{l})$ on Whatman LK5DK linear plates (Fisher Scientific), with a chloroform-only and cholesterol standard control run concurrently on each plate. The plates were put through two phases of development in separate chambers in a method modified from [25]. Phase 1 consisted of chloroform: methanol: acetic acid (98:2:1) and was developed up to $17 \mathrm{~cm}$. Phase 2 consisted of hexane: ethyl ether: acetic acid (96:4:0.2) and was developed to the top of the plate. Plates were left to dry and areas corresponding to lipids were identified by exposure to iodine vapour and marked. After 2-12 h (when iodine disappeared) the spots corresponding to lipids were scraped into scintillation vials and counted for ${ }^{3} \mathrm{H}$ - and ${ }^{14} \mathrm{C}$-radioactivity.

\section{Lipid classification}

The spot corresponding to cholesterol (chol) was first identified by co-migration with the cholesterol standard, and subsequently confirmed by infrared spectroscopy (IR). Lipids were classified using IR; spots corresponding to free fatty acid (FFA), triglyceride (TG), and cholesterol ester (CE) were examined using IR and confirmed by comparison to the separation of simple lipids by similar solvent systems [26].

\section{Plasma cholesterol}

Total plasma cholesterol concentration was measured using a commercially available spectrophotometric assay (CIMA Scientific, De Soto, TX, USA). A $10 \mu$ l volume of plasma was added to $1 \mathrm{~mL}$ of colour reagent and incubated at $37^{\circ} \mathrm{C}$ for $10 \mathrm{~min}$. The absorbance was read at 515 $\mathrm{nm}$ and the concentration of the unknown samples was calculated in comparison with a calibration standard.

\section{Statistical analysis}

Treatment differences were tested using a nested analysis of variance (ANOVA; done manually using Microsoft Office Excel 2003) with tank as the nesting factor. If treat- 
ment differences were present $(\mathrm{p}<0.05)$ and the data were parametric, Holm-Sidak tests were performed using Sigmastat 3.0 (SPSS Corp, Chicago, IL) to identify the different treatment groups. If the data were non-normal or had unequal variances, non-parametric Dunn's tests were performed. Systat 10.2 (SPSS Inc, Chicago, IL) was used to perform analysis of covariance (ANCOVA) on gonad and body weight data to determine if there were differences in gonad size among treatment groups.

\section{Results \\ GSI}

Male and female fish had developing gonads at the early to mid-recrudescence stage, as evidenced by the state of the gonads at the time of sampling. There were no differences in gonad weight relative to body weight as compared to controls in male and female fish. Male GSI values, mean $\pm \operatorname{SEM}(\mathrm{N})$, were $1.10 \pm 0.2(9), 0.7 \pm 0.3$ (11) and $1.78 \pm 0.3$ (11) for control, $\beta$-sit and $E_{2}$ treatment groups, respectively. Male $\beta$-sit-treated fish had significantly smaller gonads than the $\mathrm{E}_{2}$ treatment group $(\mathrm{p}=$ $0.032)$. The GSI values for female control, $\beta$-sit and $E_{2}$ treated-fish were $2.80 \pm 0.8$ (15), $1.9 \pm 0.5$ (13) and 2.46 \pm 0.4 (13), respectively.

\section{Plasma testosterone}

$\beta$-Sit significantly reduced plasma $\mathrm{T}$ concentrations in male fish relative to controls ( $\mathrm{p}<0.001$; Figure 2$)$, while plasma $\mathrm{T}$ concentrations of $\beta$-sit-exposed females were not different from those of control fish. The $\beta$-sit treated females had significantly lower plasma $\mathrm{T}$ than the $\mathrm{E}_{2}$ treatment group $(\mathrm{p}=0.034)$.

\section{De novo cholesterol assay}

The cholesterol extraction protocol recovered $90.7 \pm 0.6 \%$ of the ${ }^{3} \mathrm{H}$-cholesterol, indicating a high extraction efficiency. There were no differences in ${ }^{14} \mathrm{C}$-acetate incorporation into cholesterol or CE in male (Figure 3) or female (Figure 4) fish. There was significantly higher ${ }^{14} \mathrm{C}$-acetate incorporation into FFAs in male control fish than in either $\beta$-sit or $E_{2}$ treatment groups. There were no treatment differences for either sex in cholesterol: CE or cholesterol: TG ratio (data not shown).

\section{Plasma cholesterol}

Male $\beta$-sit-treated fish had significantly higher total plasma cholesterol concentrations than control fish $(\mathrm{p}=$ 0.027; Figure 5). There were no differences in female plasma cholesterol concentrations.

\section{Discussion}

The de novo cholesterol biosynthetic pathway begins with the acquisition of acetyl-CoA, but commitment to cholesterol synthesis occurs subsequent to acetyl-CoA production. TG biosynthesis also utilizes acetyl-CoA as a substrate, potentially diverting substrate from the de novo cholesterol synthetic pathway [27]. TG is the primary metabolic energy storage molecule in fish where upwards of $80 \%$ of total body lipid composition is present as TG [7]. The current study suggests acetyl-CoA is preferentially directed towards TG synthesis over cholesterol in early to mid-recrudescing gonads of male and female goldfish. Ovarian tissue preferentially uses lipoprotein-derived cholesterol as a steroidogenic substrate [6], therefore, a large de novo cholesterol biosynthetic capacity was not expected in female gonads. The higher ${ }^{14} \mathrm{C}$-TG enrichment in ovarian tissue is consistent with an increased TG demand during reproductive development; growing oocytes incorporate high concentrations of TG to provide metabolic fuel for developing embryos [28]. Similar studies on trout (Salmo gairdneri) have shown high acetate incorporation towards TG synthesis during later gonadal development [45]. In testicular tissue it is believed that $d e$ novo-derived cholesterol is the primary substrate for steroidogenesis [2], therefore, more substantial ${ }^{14} \mathrm{C}$-acetate incorporation towards cholesterol was predicted. In contrast, ${ }^{14} \mathrm{C}$ was enriched 6 -fold and 3-fold higher towards TG and FFA than towards cholesterol and CEs. This higher level of de novo TG synthesis was consistent in all male treatment groups.

While fish testes generally have low lipid content that varies with season and reproductive stage [7], the high plasma $\mathrm{T}$ concentrations in male control fish suggest $\mathrm{T}$ synthesis (and thus steroidogenic substrate) was not impaired at the reproductive stage in the present study. The ${ }^{14} \mathrm{C}$-acetate incorporation data suggest testis tissue may direct acetyl-coA towards TG formation when cholesterol availability to steroidogenesis is not limiting. Plasma cholesterol concentrations were above $200 \mathrm{mg} / \mathrm{dL}$ for both sexes in all treatment groups, suggesting cholesterol and steroidogenic capacity were not limited at the point of circulatory uptake or de novo synthesis of cholesterol. The absence of a reduction in plasma $T$ in the $E_{2}$ treated fish and its significant decrease in $\beta$-sit exposed animals provides evidence of a unique, non-estrogenic mechanism of $\beta$-sit endocrine effects. Additionally, the depression of FFA synthesis by both $\beta$-sit and $E_{2}$ treatment demonstrates common effects on lipid dynamics in exposed fish. Previous studies have established that $\beta$-sit changes plasma cholesterol dynamics and has endocrine effects distinct from $E_{2}[29]$. The regulation of steroidogenesis is a multifaceted feedback system among the hypothalamus, pituitary and the gonads, known as the HPG axis, therefore impairment of function can occur at multiple levels. MacLatchy et al. [28] demonstrated that $\beta$-sit does not alter plasma luteinising hormone (LH) concentration, while $\mathrm{E}_{2}$ interacts with the HPG axis extensively [30-32]. In particular, $\mathrm{E}_{2}$ and $\mathrm{FSH}$ are involved in regulating lipid accumulation in the ovaries of salmon (Oncorhynchus kis- 


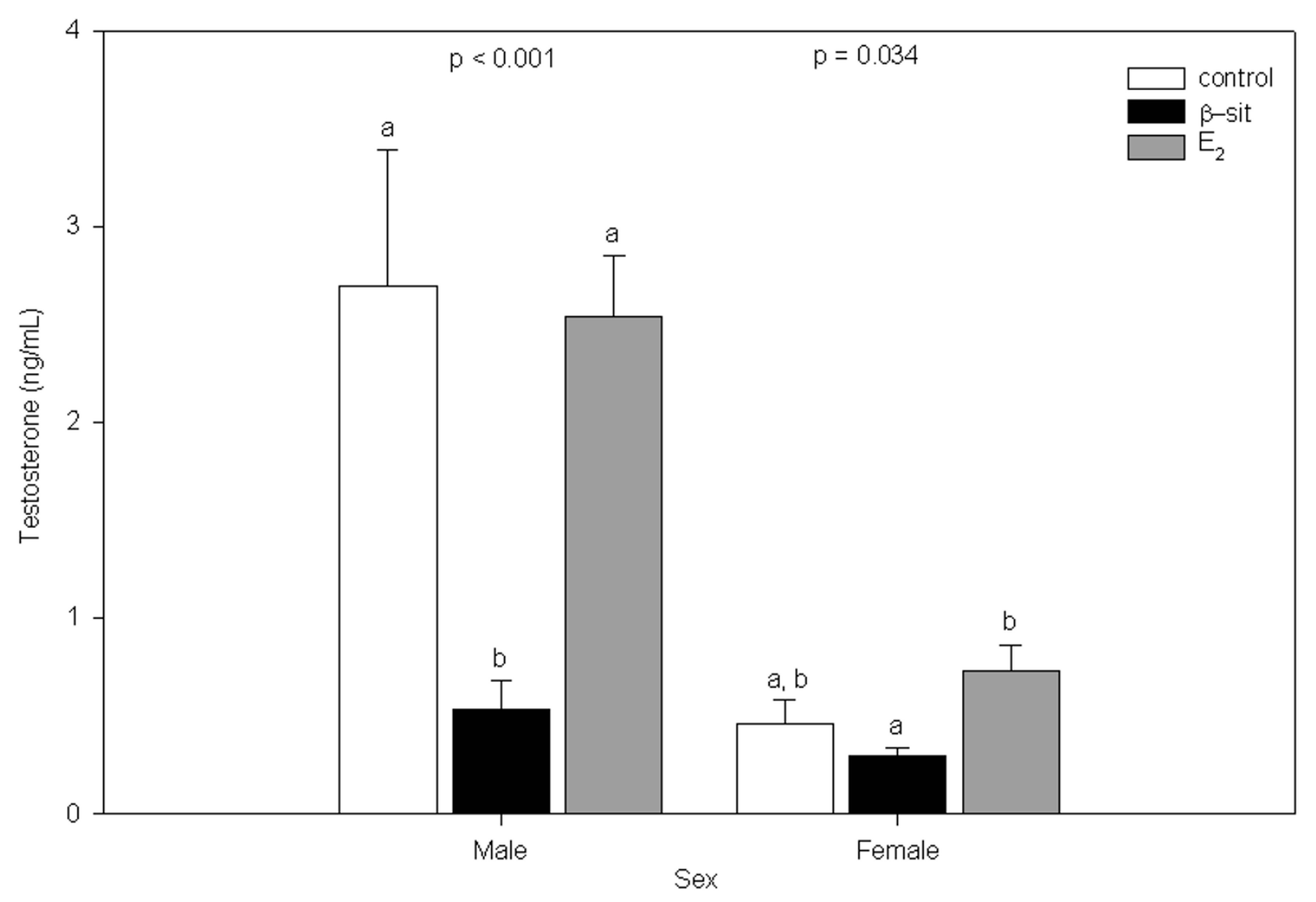

\section{Figure 2}

Plasma testosterone concentration $(\mathrm{ng} / \mathrm{mL})$ in male and female goldfish exposed to control, $\beta$-sit $(200 \mu \mathrm{g} / \mathrm{g})$ and $\mathrm{E}_{2}(\mathrm{I} 0 \mu \mathrm{g} / \mathrm{g})$ via Silastic ${ }^{\circledR}$ implants for 2 I days. Bars represent means \pm SE. Different letters indicate treatments that are significantly different $(P$ $<0.05)$.

utch), thereby demonstrating a potential for $\mathrm{E}_{2}$ lipidemic effects [33]. The increase in plasma cholesterol seen currently in the male $\beta$-sit treatment group and an absence in the $\mathrm{E}_{2}$ treatment group, demonstrates independent effects of $\beta$-sit on plasma cholesterol concentration, likely caused by a mechanism distinct from an $\mathrm{E}_{2}$ feedback system. Evidence of $\beta$-sit interacting with lipid synthetic enzymes in humans [18] would suggest disruption likely occurs at the level of cholesterol biosynthesis. Further studies examining lipid synthetic enzyme kinetics will provide good insight towards understanding the interaction of $\beta$-sit and $\mathrm{E}_{2}$ with the cholesterol synthetic pathway.

The goldfish used in the current study were undergoing early to mid-recrudescence, based on preceding acclimation conditions, observations during sampling, GSI values and plasma T concentrations. Reproductive development in goldfish is highly regulated by changes in environmen- tal parameters such as photoperiod and water temperature [34] and the laboratory environmental conditions for this study were designed to initiate recrudescence (15$\left.16^{\circ} \mathrm{C} ; 14 \mathrm{~h} \mathrm{~L}: 10 \mathrm{~h} \mathrm{D}\right)$. Fish experience low circulating cholesterol concentrations during sexual maturation, and it is known plasma lipids are variable and influenced by reproductive state [10]. Testis lipid content varies with season and, therefore, reproductive development [7]. It is thus likely that sensitivity to lipid-altering chemicals may also vary with reproductive state, presenting contradicting results dependent on the specific physiology and lipid metabolism of the particular gonadal stage at the time of exposure. This appears to be the case with $\beta$-sit, which affects endocrine endpoints such as plasma $\mathrm{T}$ and cholesterol concentration differently in males and females at different reproductive states and exposure durations. For example, in a long-term $\beta$-sit exposure covering a 5month period of gonadal development and starting prior 


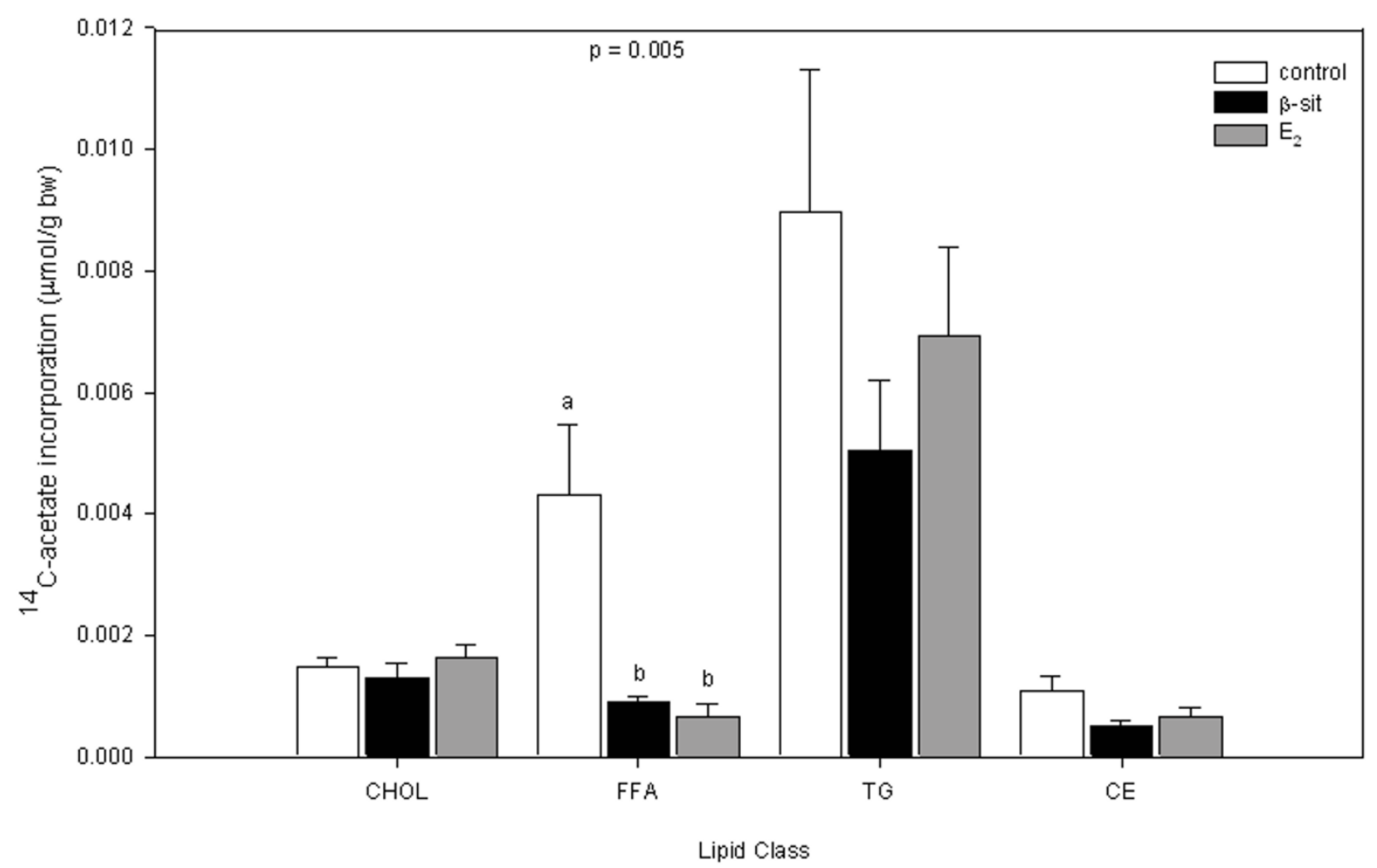

Figure 3

Gonad lipid ${ }^{14} \mathrm{C}$-acetate incorporation $(\mu \mathrm{mol} / \mathrm{g}$ bw) toward cholesterol (chol), free fatty acid (FFA), triglyceride (TG) and cholesterol ester (CE) in male goldfish exposed to control, $\beta$-sit $(200 \mu \mathrm{g} / \mathrm{g})$ and $\mathrm{E}_{2}(\mathrm{I} 0 \mu \mathrm{g} / \mathrm{g})$ via Silastic ${ }^{\circledR}$ implants for $2 \mathrm{I}$ days. Values are presented as means \pm SE. Different letters indicate treatments that are significantly different $(p<0.05)$.

to the initiation of recrudescence, there were no effects on plasma $\mathrm{T}$ or cholesterol concentration by $\beta$-sit during recrudescence [35]. However, at the initiation of a subsequent cycle of gonadal development, in the same 5month exposure, male fish experienced significant reductions in plasma $\mathrm{T}$ [36]. In the current study, plasma cholesterol concentrations increased in the $\beta$-sit treatment group, an effect in contrast to previous reports [14,15], indicating $\beta$-sit can also have variable effects on plasma lipids. It is, therefore, critical to interpret endocrine effects of $\beta$-sit exposure with conscience to the reproductive stage at the time of exposure and sampling. Further, the complex and intricate nature of the regulation of steroidogenesis by the HPG axis makes the interpretation of plasma hormone data challenging. The reduction in plasma $\mathrm{T}$ in male fish exposed to $\beta$-sit but not $\mathrm{E}_{2}$ likely results from different sensitivities of the HPG axis to estrogenic control at different stages of the reproductive cycle; male and female fish were not sensitive to down-regulation of $\mathrm{T}$ synthesis by $E_{2}$ in the present study. The impact of $\beta$-sit exposure on plasma $\mathrm{T}$ would, therefore, appear to be caused by nonestrogenic mechanisms, likely related to limited cholesterol availability to the steroidogenic pathway [16]. Steroidogenic acute regulatory protein (StAR) has been identified as a mitochondrial cholesterol transporter [37], and $\beta$-sit has been shown to reduce StAR mRNA abundance in male goldfish [36]. Given that de novo cholesterol synthesis was unaffected by $\beta$-sit exposure and plasma cholesterol concentrations were not decreased, it is highly possible that cholesterol delivery to the steroidogenic pathway is impaired rather than intracellular cholesterol availability.

Male and female goldfish responded differently to $\beta$-sit and $\mathrm{E}_{2}$ exposure; plasma testosterone and cholesterol concentrations were unchanged by $\beta$-sit in female fish. Few 


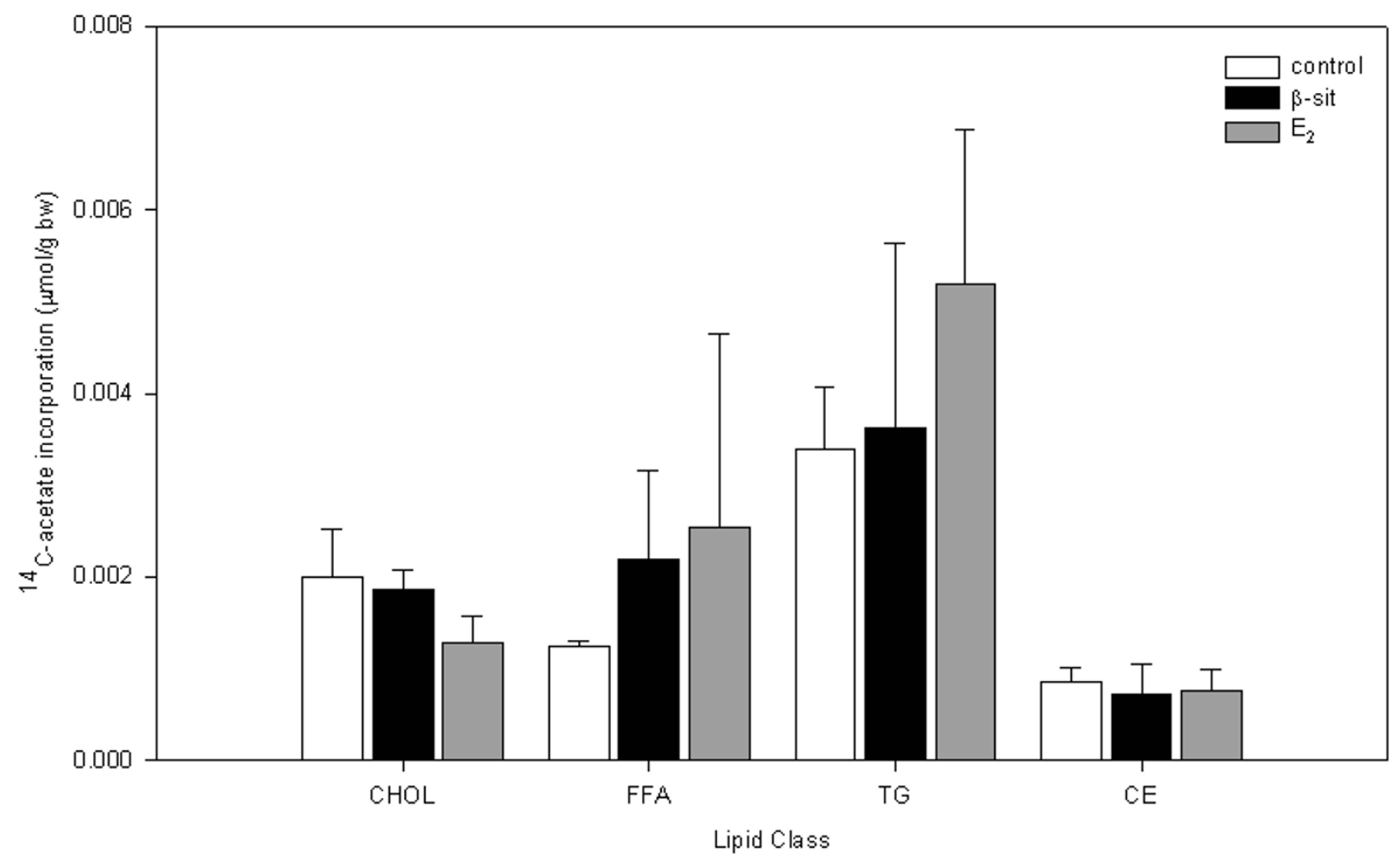

\section{Figure 4}

Gonad lipid ${ }^{14} \mathrm{C}$-acetate incorporation ( $\mu \mathrm{mol} / \mathrm{g}$ bw) towards cholesterol (chol), free fatty acid (FFA), triglyceride (TG) and cholesterol ester (CE) in female goldfish exposed to control, $\beta$-sit $(200 \mu \mathrm{g} / \mathrm{g})$ and $\mathrm{E}_{2}(\mathrm{I} 0 \mu \mathrm{g} / \mathrm{g})$ via Silastic ${ }^{\circledR}$ implants for $2 \mathrm{I}$ days. Values are presented as means \pm SE. There are no treatment differences $(p>0.05)$.

studies have examined the responses of both male and female fish to $E_{2}$ or $\beta$-sit exposures. Similar steroid responses in male and female goldfish (male GSI = 3.9 $4.9 \%$, female GSI $=4.5-6.2 \%$ ) to varying concentrations of sitosterol have been reported [29]; both sexes experience significant reductions in circulating $\mathrm{T}$ in response to $\beta$-sit, but not $\mathrm{E}_{2}$. In contrast, the present research found male fish to be more sensitive to reductions in plasma $\mathrm{T}$ following $\beta$-sit exposure than females. These differences in plasma hormone response between studies is likely at least partly due to differences in gonadal stage at the time of the exposures (current experiments, male GSI $=0.7$ $1.78 \%$, female GSI $=1.9-2.8 \%$ ) and, therefore, a different physiological environment in which exogenous chemicals interact with gonadal tissue. Further, circulating $\mathrm{E}_{2}$ is a normal physiological reproductive stage-dependent phenomenon in female fish [38], therefore feedback systems and metabolic responses to exogenous $E_{2}$ exist in females that are not normally activated or required in male fish. In the present study, however, male fish were more sensitive to $\beta$-sit than female fish, and generally neither plasma $\mathrm{T}$ or cholesterol were sensitive to $\mathrm{E}_{2}$ in either sex. It appears there are sex differences in sensitivity to $\beta$ sit with regard to plasma hormones and cholesterol and these varying sensitivities are likely related to reproductive stage and the associated endogenous regulation of gonadal development.

A quantitative, physiologically-relevant indication of steroidogenic output can be determined using gonadal in vitro incubation methods that measure steroidogenic output by gonadal tissue [39]. Reported rates of $\mathrm{T}$ production in goldfish testis range from $1 \mathrm{pg} / \mathrm{g}$ (unknown GSI) [40] to $20 \mathrm{pg} / \mathrm{mg}$ (GSI 2.2\%), with the latter corresponding to a plasma T concentration of $3.0 \mathrm{ng} / \mathrm{mL}$ [14]. In vitro steroid biosynthetic capacity was not measured in the current 


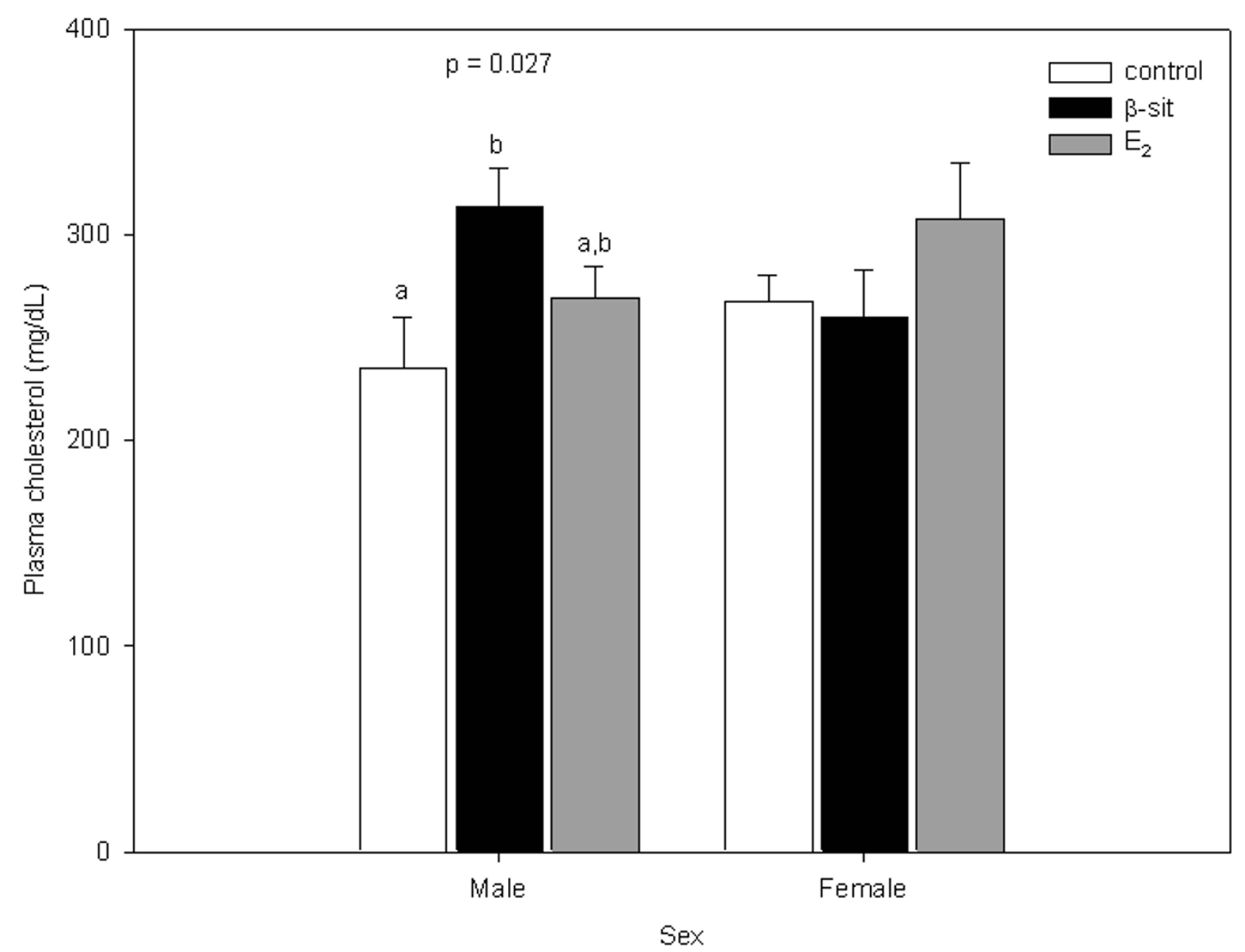

Figure 5

Plasma cholesterol concentrations $(\mathrm{mg} / \mathrm{dL})$ in male and female goldfish exposed to control, $\beta$-sit $(200 \mu g / g)$ and $E_{2}(I 0 \mu g / g)$ via Silastic implants for $2 \mathrm{I}$ days. Bars represent means \pm SE. Different letters indicate treatments that are significantly different $(P$ $<0.05)$.

study due to limited gonadal tissue availability; however, control male plasma T concentrations were comparable to those reported by MacLatchy \& Van Der Kraak [28]. Therefore, an estimate of the cholesterol requirements for T production in the male control group of the present study can be calculated using the in vitro biosynthetic capacity reported by MacLatchy and Van Der Kraak (20 pg/mg over an 18-h period). Cholesterol is used for additional cellular functions in the testis (storage, plasma membrane integrity, synthesis of other steroid hormones), therefore, any estimation of cholesterol requirements based solely on $\mathrm{T}$ production will be highly underestimated. Given this limitation, an estimate of $2.9 \times 10^{-10}$ moles of cholesterol were required to produce $20 \mathrm{pg}$ of $\mathrm{T}$ (using a 1:1 testoster- one: cholesterol stoichiometry). In the current study, control male fish incorporated $1.47 \times 10^{-9}$ moles of acetate, or $8.8 \times 10^{14}$ molecules towards cholesterol synthesis during the 18-h incubation period. Given an 18:1 stoichiometry (18 molecules of acetate for each cholesterol synthesized) [41], this equates to $8.2 \times 10^{-11}$ moles of cholesterol synthesized de novo. Additional studies have measured gonadal tissue cholesterol concentrations from recrudescing male goldfish and report $22.6 \mathrm{mg}$ cholesterol/g tissue [35]. This equates to $5.8 \times 10^{-5} \mathrm{~mol} / \mathrm{g}$, which if corrected to $25 \mathrm{mg}$ of testis tissue as used in the current study, estimates $1.5 \times 10^{-6} \mathrm{~mol}$ of endogenous cholesterol is present in each de novo testis sample. Therefore, the de novo contribution $\left(8.2 \times 10^{-11}\right)$ is very small relative to the total cho- 
lesterol pool $\left(1.5 \times 10^{-6}\right)$. However, the estimated de novo synthetic capacity is within an order of magnitude of the estimated steroidogenic needs for T synthesis $\left(2.9 \times 10^{-10}\right)$ and could make a significant contribution to the steroidogenic substrate pool.

Identification of lipid classes was limited to cholesterol, TG, FFA and CE; it is highly likely that ${ }^{14} \mathrm{C}$-acetate was incorporated to phospholipids and monoacyl- and diacylglycerols as well [26]. Weigand and Idler [45] examined acetate incorporation to various lipid classes in ovarian tissue of trout and found that while polar lipids were favoured when GSI was small, TG was preferentially synthesized in fish with larger GSI. In catfish (Heteropneustes fossilis), plasma and ovarian phospholipid concentrations followed the same trends as cholesterol and TG throughout the reproductive cycle [42] and high plasma phospholipid concentrations have been documented during maturation in goldfish [43]. Given such indications that dominant gonadal lipid classes can vary throughout the reproductive cycle, it should be noted that broad conclusions on gonadal lipid synthesis are limited to only the neutral lipid classes in the current study.

The high ${ }^{14} \mathrm{C}$-acetate incorporation towards FFA in control fish was absent in the corresponding male $\beta$-sit and $E_{2}$ treatment groups. Phytosterols detrimentally affect cholesterol metabolism in the human disease sitosterolemia by inhibiting endogenous cholesterol biosynthesis [19], therefore, inhibitory impacts of sitosterol exposure on fish were expected. The first enzyme subsequent to the formation of acetyl Co-A in the cholesterol biosynthetic pathway, acetoacetyl CoA thiolase, is down-regulated in sitosterolemic patients [18] and phytosterols have been shown to down-regulate numerous other cholesterol biosynthetic enzymes in mammals [44]. The current study did not examine enzyme kinetics. The three week $\beta$-sit exposure prior to gonadal tissue incubation with ${ }^{14} \mathrm{C}$-acetate would serve to establish physiological conditions similar to those in sitosterolemia, where tissues were exposed to higher than normal concentrations of plant sterols. Surprisingly, there were no differences in ${ }^{14} \mathrm{C}$ enrichment of cholesterol or CEs in male or female fish, indicating no changes in de novo cholesterol synthetic capacity among treatment groups. The lower ${ }^{14} \mathrm{C}$-acetate incorporation to FFA in male $\beta$-sit- and $\mathrm{E}_{2}$-treated gonads suggests both substances have the capacity to down-regulate endogenous FFA synthesis in gonadal tissue. Further, the similar effect by both substances demonstrates the capacity of $\beta$-sit to act with estrogenic properties in vivo. Therefore, while the current study provides evidence that $\beta$-sit has non-estrogenic endocrine disrupting behaviour, as evidenced by decreased plasma $\mathrm{T}$, it also has effects similar to estrogen in terms of its effects on FFA synthesis in the gonads. There is no evidence in the present study to suggest $\beta$-sit has effects on de novo cholesterol biosynthesis at this reproductive stage for either sex; there is no variation in cholesterol synthesis in the gonads of fish exposed to $\beta$-sit or $\mathrm{E}_{2}$.

\section{Conclusion}

The present study clearly demonstrates that ovarian and testicular tissues have comparable capacities for de novo cholesterol synthesis at early to mid-recrudescence, and neither $\beta$-sit nor $\mathrm{E}_{2}$ treatment disrupts gonadal cholesterol biosynthesis in goldfish at this reproductive stage. Further, differences between $\beta$-sit and $E_{2}$ exposure effects were demonstrated, suggesting the mechanisms of action of $\beta$ sit occur at points outside the HPG axis to yield effects on steroid biosynthesis and lipid metabolism.

\section{Authors' contributions}

RLS originated the detailed experimental design, some of the study concepts and methodology; carried out the experimental exposures, steroid and lipid analyses, statistical analyses; and drafted the manuscript. MD participated in the infrared spectroscopy validation of lipid types. DLM initiated the original study concepts, participated in design of the study and helped to draft the manuscript. All authors read and approved the final manuscript.

\section{Acknowledgements}

The following students and technicians at the University of New Brunswick (Saint John) helped with the sampling of fish: W. Cushnie, J. Adams, L. Bowron, A. Hicks, and M. Hanson-Lee. A. Brown, M. Beyea and M. Arend are thanked for their input towards developing the lipid extraction protocol and $\mathrm{K}$. Cummings is thanked for assistance with the maintenance and care of the fish. Funding was provided by the Natural Sciences and Engineering Research Council (NSERC) Discovery Grant program (D.L. MacLatchy) and the Canadian Water Network (D.L. MacLatchy; P.I. K. Munkittrick). Animal care protocols were approved by the UNB Saint John Animal Care Committee, following Canadian Council on Animal Care guidelines for fish.

\section{References}

I. Scott AP: Reproductive endocrinology of fish. In Fundamentals of comparative vertebrate endocrinology Edited by: Chester-Jones IIPMPJG. New York, Plenum Press; 1987:223-256.

2. Pederson RC: Cholesterol biosynthesis, storage, and mobilization in steroidogenic organs. In Biology of Cholesterol Edited by: Yeagle PL. Boca Raton, Florida, CRC Press, Inc.; 1988:39-69.

3. Rogie A, Skinner ER: The roles of the intestine and liver in the biosynthesis of plasma lipoproteins in the rainbow trout, Salmo Gairdnerii richardson. Comp Biochem Physiol 1985, 8 I B(2):285-289.

4. Skinner ER, Rogie $A$ : The isolation and partial characterization of the serum lipoproteins and apolipoproteins of the rainbow trout. Biochem J 1978, 173:507-520.

5. Maxfield FR, Wustner D: Intracellular cholesterol transport. J Clin Invest 2002, I 10(7):891-898.

6. Gwynne JT, Strauss FF: The role of lipoproteins in steroidogenesis and cholesterol metabolism in steroidogenic glands. Endocrine Reviews 1982, 3(3):299-329.

7. Henderson RJ, Tocher DR: The lipid composition and biochemistry of freshwater fish. Prog Lipid Res 1987, 26:28I-347.

8. Chapman MJ: Animal lipoproteins: chemistry, structure, and comparative aspects. J Lipid Res 1980, 21:789-853. 
9. Norum KR, Berg T, Helgerud P, Drevon CA: Transport of cholesterol. Physiol Rev 1983, 63(4): |343-1419.

10. Babin PJ, Vernier JM: Plasma lipoproteins in fish. J Lipid Res 1989, 30:467-489.

11. Larsson A, Fange R: Cholesterol and free fatty acids (FFA) in the blood of marine fish. Comp Biochem Physiol 1977, 57B: $19 \mid-196$.

12. Bloch K: The biological synthesis of cholesterol. Science 1965, 3692(350): 19-28.

13. Schuler LA, Scavo L, Kirsch TM, Flickinger GL, Strauss JF: Regulation of de novo biosynthesis of cholesterol and progestins, and formation of cholesteryl ester in rat corpus luteum by exogenous sterol. J Biol Chem 1979, 254(I 7):8662-8668.

14. MacLatchy D, Van Der Kraak G: Effects of the phytoestrogen bsitosterol on the reproductive endocrine status of goldfish. Toxicol Appl Pharmacol 1995, 134:305-312.

15. Gilman Cl, Leusch FDL, Breckenridge WC, MacLatchy DL: Effects of a phytosterol mixture on male fish plasma lipoprotein fractions and testis P450scc activity. Gen Comp Endocrinol 2003, 130: 172-184.

16. Leusch FDL, MacLatchy D: In vivo implants b-sitosterol cause reductions of reactive cholesterol pools in mitochondria isolated from gonads of male goldfish (Carassius auratus). Gen Comp Endocrinol 2003, 134:255-263.

17. Tremblay L, Van Der Kraak G: Use of a series of homologous in vitro and in vivo assays to evaluate the endocrine modulating actions of b-sitoserol in rainbow trout. Aquat Toxicol 1998, 43:149-162.

18. Honda A, Salen G, Nguyen LB, Tint GS, Batta AK, Shefer S: Downregulation of cholesterol biosynthesis in sitosterolemia: diminished activities of acetoacetyl-CoA thiolase, 3hydroxy-3-methylglutaryl-CoA synthase, reductase, squalene synthase, and 7-dehydrocholesterol delta7-reductase in liver mononuclear leukocytes. J Lipid Res 1998, 39:44-50.

19. Salen G, Shore V, Tint GS, Forte T, Shefer S, Horak I, Horak E, Dayal $B$, Nguyen L, Batta AK, Lindgren FT, Kwiterovich PO: Increased sitosterol absorption, decreased removal, and expanded body pools compensate for reduced cholesterol synthesis in sitosterolemia with xanthomatosis. I Lipid Res 1989, 30:1319-1330.

20. Coutinho EM, Carols de Souza J, Athayde C, Barbosa IC, Alvarez F, Brache V, Zhi-Ping G, Emuveyan EE, Adekunle AO, Devoto L, Shaaban MM, Salem HT, Affandi B, Mateo de Acosta O, Mati J, Ladipo OA: Multicenter clinical trial on the efficacy and acceptability of a single contraceptive implant of nomegestrol acetate, Uniplant. Contraception 1996, 53:121-125.

21. Diaz S, Pavez M, Miranda P, Robertson DN, Sivin I, Croxatto HB: A five-year clinical trial of levonorgestrel silastic implants (Norplant TM). Contraception 1982, 25(5):447-456.

22. McMaster ME, Munkittrick KR, Van Der Kraak G]: Protocol for measuring circulating levels of gonadal sex steroids in fish. Can Tech Rept Fish Aquat Sci 1992, 1836:29.

23. Dubé MG, Maclatchy DL: Endocrine responses of Fundulus heteroclitus to effluent from a bleached-kraft pulp mill before and after installation of reverse osmosis treatment of waste stream. Environ Toxicol Chem 2000, 1 (1II):2788-2796.

24. Azhar S, Khan IC Y.-D. I., Reaven GM, Gibori G: Regulation of luteal cell 3-hydroxy-3-methylglutaryl coenzyme A reductase activity by estradiol. Biol Reprod 1985, 32:333-34I.

25. Bitman J, Wood DL, Ruth JM: Two-stage, one-dimensional thin layer chromatographic method for separation of lipid classes. J Liq Chromat 198I, 4(6): I007-1021.

26. Christie WW: Lipid analysis: Isolation, separation, identification and structural analysis of lipids. 3rd edition. Bridgwater, England, The Oily Press; 2003:416.

27. Horton JD, Goldstein JL, Brown MS: SREBPs: activators of the complete program of cholesterol and fatty acid synthesis in the liver. J Clin Invest 2002, I 09: I I 25- I I 3 I.

28. Jobling M: Environmental Biology of Fishes. In Fish and Fisheries Series Volume 16. New York, Chapman \& Hall; 1995:455

29. MacLatchy D, Peters L, Nickle J, Van Der Kraak G: Exposure to bsitosterol alters the endocrine status of goldfish differently than I7B-estradiol. Environ Toxicol Chem 1997, I6(9): | 895- 1904.

30. Whitten PL, Naftolin F: Reproductive actions of phytoestrogens. Bailliere Clin Endocrinol 1998, I 2(4):667-690.
31. Van Der Kraak G, Zacharewski T, Janz DM, Sanders BM, Gooch JW: Comparative endocrinology and mechanisms of endocrine modulation in fish and wildlife. Principles and processes for evaluating endocrine disruption :97-119.

32. Colborn T, vom Saal FS, Soto AM: Developmental effects of endocrine-disrupting chemicals in wildlife and humans. Env Health Perspec 1993, I0I(q):378-384.

33. Campbell B, Dickey J, Beckman B, Young G, Pierce A, Fukada H, Swanson P: Previtellogenic oocyte growth in salmon: relationships among body growth, plasma insulin-like growth factorI, estradiol-I 7 beta, follicle-stimulating hormone and expression of ovarian genes for insulin-like growth factors, steroidogenic-acute regulatory protein and receptors for gonadotropins, growth hormone, and somatolactin. Biol Repro 2006, 75:34-44.

34. Hervey GF, Hems J: The goldfish. London, Faber and Faber; 1968:271.

35. Sharpe RL, MacLatchy DLM: Lipid dynamics in goldfish (Carassius auratus) during a period of gonadal recrudescence: effects of b-sitosterol and I7b-estradiol exposure. Comp Biochem Physiol 2006, in press:

36. Sharpe RL, Woodhouse A, Moon TW, Trudeau VL, MacLatchy DLM: b-sitosterol and I7b-estradiol alter gonadal steroidogenic acute regulatory protein (StAR) expression in goldfish, Carassius auratus. Gen Comp Endocrinol 2006, in press:.

37. Stocco DM, Clark BJ: The role of the steroidogenic acute regulatory protein in steroidogenesis. Steroids 1997, 62:29-36.

38. Peter RE, Crim LW: Reproductive endocrinology of fishes: gonadal cycles and gonadotropin in teleosts. Ann Rev Physiol 1979, 41:323-335.

39. McMaster ME, Munkittrick KR, Jardine J], Tobinson RD, Van Der Kraak G]: Protocol for measuring in vitro steroid production by fish gonadal tissue. Can Tech Rept Fish Aquat Sci 1995, 196 I:78.

40. Parrott JL, Jardine J], Blunt BR, McCarthy LH, McMaster ME, Wood CS, Robers J, Carey JH: Comparing biological responses to mill process changes: a study of steroid concentrations in goldfish exposed to effluent and waste streams from a canadian bleached sulphite mill. Wat Sci Tech 1999, 40(1 1-12): II5-I2I.

4I. Lehninger AL, Nelson DL, Cox MM: Principles of biochemistry. 2nd edition. New York, Worth Publishers; 1993.

42. Singh PB, Singh TP: Seasonal correlative changes between sex steroids and lipid levels in the freshwater female catfish, Heteropneustes fossilis (Bloch). J Fish Biol 1990, 37:793-802.

43. Wiegand MD, Peter RE: Effects of sex steroids on plasma lipids in the goldfish, Carassius auratus. Can / Zool 1980, 58:967-972.

44. Yang C, Yu L, Li W, Xu F, Cohen JC, Hobbs HH: Disruption of cholesterol homeostasis by plant sterols. J Clin Invest 2004, I | 4(6):8|3-822.

45. Wiegand MD, Idler DR: Synthesis of lipids by the rainbow trout (Salmo gairdner) ovary in vitro. Can J Zool 1982, 60(II):2683-2693.
Publish with Biomed Central and every scientist can read your work free of charge

"BioMed Central will be the most significant development for disseminating the results of biomedical research in our lifetime. "

Sir Paul Nurse, Cancer Research UK

Your research papers will be:

- available free of charge to the entire biomedical community

- peer reviewed and published immediately upon acceptance

- cited in PubMed and archived on PubMed Central

- yours - you keep the copyright
BioMedcentral 